\title{
An Evaluation of Multipass Narrow Gap Laser Welding as a Candidate Process for the Manufacture of Nuclear Pressure Vessels
}

Dol:

10.1016/j.ijpvp.2017.08.004

\section{Document Version}

Accepted author manuscript

Link to publication record in Manchester Research Explorer

Citation for published version (APA):

Feng, J. C., Rathod, D. W., Roy, M., Francis, J., Guo, W., Irvine, N., Vasileiou, A., Sun, Y. L., Smith, M., \& Li, L. (2017). An Evaluation of Multipass Narrow Gap Laser Welding as a Candidate Process for the Manufacture of Nuclear Pressure Vessels. International Journal of Pressure Vessels and Piping, 157. https://doi.org/10.1016/j.jpvp.2017.08.004

\section{Published in:}

International Journal of Pressure Vessels and Piping

\section{Citing this paper}

Please note that where the full-text provided on Manchester Research Explorer is the Author Accepted Manuscript or Proof version this may differ from the final Published version. If citing, it is advised that you check and use the publisher's definitive version.

\section{General rights}

Copyright and moral rights for the publications made accessible in the Research Explorer are retained by the authors and/or other copyright owners and it is a condition of accessing publications that users recognise and abide by the legal requirements associated with these rights.

\section{Takedown policy}

If you believe that this document breaches copyright please refer to the University of Manchester's Takedown Procedures [http://man.ac.uk/04Y6Bo] or contact uml.scholarlycommunications@manchester.ac.uk providing relevant details, so we can investigate your claim.

\section{OPEN ACCESS}




\title{
An Evaluation of Multipass Narrow Gap Laser Welding as a Candidate Process for the Manufacture of Nuclear Pressure Vessels
}

\author{
J. C. Feng* ${ }^{\text {a,b }}$, D. W. Rathod ${ }^{\mathrm{a}}$, M. J. Roy ${ }^{\mathrm{a}}$, J. A. Francis ${ }^{\mathrm{a}}$, W. Guo ${ }^{\mathrm{a}}$, N. M. Irvine ${ }^{\mathrm{c}}$, A. N.

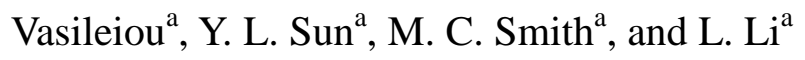

${ }^{a}$ School of Mechanical, Aerospace and Civil Engineering, The University of Manchester, Manchester M13 9PL, U. K.

${ }^{\mathrm{b}}$ Shanghai Rui Rong Laser Welding Technology Co. Ltd., Shanghai 201306, China

${ }^{c}$ Dalton Nuclear Institute, The University of Manchester, Manchester M13 9PL, U.K.

* Corresponding author: Building 2, 1500 Cenglin Road, Pudong New Area, Shanghai, P.R. China 201306. Tel.: +86 21-60977170; fax: +86 21-60977177.

E-mail: fengjc@rr-laser.cn; fjc2002@sina.com

\begin{abstract}
Nuclear pressure vessels are currently fabricated using arc welding processes. Recently, considerable effort has been directed at the development of electron beam welding as an alternative fabrication technique owing to the substantial productivity gains it would offer. However, little attention has been directed at laser-based techniques. In this work we evaluate the potential for applying multipass narrow-gap laser welding (NGLW) to the fabrication of nuclear pressure vessels, based on the characterization of a $30 \mathrm{~mm}$ thick weld in SA508 steel. Although still a multipass process, the number of passes is reduced in comparison to an arc weld of the same thickness, and the deposition of successive passes provides a degree of tempering to previously deposited weld metal in a way that the electron beam welding process does not. Principal engineering challenges
\end{abstract}


for the implementation of multipass NGLW include the achievement of appropriate joint fit-up, and the shielding of a molten pool at the base of a deep and narrow weld groove.

Keywords: conduction mode welding, magnetic beam deflection, narrow-groove weld, post-weld heat treatment, single-sided weld, welding productivity.

\section{Introduction}

Historically, the welding of primary reactor components has been implemented by the exclusive use of arc welding processes. However, in recent years some attention has focused on the development of electron beam welding as a high productivity alternative to arc welding [1]. Electron beam welding offers the potential to complete steel welds in thicknesses exceeding $100 \mathrm{~mm}$ in a single weld pass, whereas the number of passes required with an arc welding process will be in the order of 100. In contrast, very little attention has been directed at laser welding owing primarily to the fact that single pass welds are not possible in such thick materials. Nevertheless, laser welding offers some advantages over electron beam welding, in that electron beam welding is prone to deflection of the beam if there is any residual magnetism within the steel, whereas laser welding is not. Furthermore, electron beam welding involves the generation of X-rays, whereas this is not the case for laser welding.

The purpose of this work is to evaluate the feasibility of using a multipass narrow-gap laser welding (NGLW) process to manufacture welds in a 
reactor-pressure-vessel steel. SA508 Grade 3 Class 1 steel was used as the test case owing to its widespread use in reactor pressure vessels (RPVs) and steam generators in nuclear fission power plants [2 - 4]. The application of laser welding to this steel was recently reported [5]. However, that work involved a single pass weld in relatively thin material (6 $\mathrm{mm}$ ) and no attention was given to the development of residual stresses, which are known to affect the long term integrity of primary nuclear components [6]. In this work we evaluate the application of multipass NGLW to $30 \mathrm{~mm}$ thick SA508 Grade 3 Class 1 steel, focusing on cross-weld tensile properties, pass-to pass tempering effects, levels of residual stress, and the extent to which stresses are relieved by post-weld heat treatment (PWHT).

\section{Experimental Methodology}

\subsection{Materials}

SA508 Grade 3 Class 1 steel typically has a yield strength in the order of $450 \mathrm{MPa}$, an ultimate tensile strength in the vicinity of $600 \mathrm{MPa}$, and it exhibits an elongation in excess of $20 \%$ [4]. In this study, four SA508 plates with dimensions of $410 \mathrm{~mm} \times 145 \mathrm{~mm}$ $\times 30 \mathrm{~mm}$ were prepared for welding. The length of the groove was approximately 270 $\mathrm{mm}$, which left segments of material intact at either end of the plate for the purpose of providing a degree of self-restraint in order to mitigate weld distortion. The filler wire that was used during welding had a diameter of $1.2 \mathrm{~mm}$. The chemical compositions for the base material and the filler wire are given in Table 1.

Table 1: Chemical compositions for SA508 Gr. 3 Cl. 1 steel and filler wire (wt.-\%). 


\begin{tabular}{llllllllllll}
\hline & $\mathrm{C}$ & $\mathrm{Si}$ & $\mathrm{Mn}$ & $\mathrm{Ni}$ & $\mathrm{Cr}$ & $\mathrm{Mo}$ & $\mathrm{V}$ & $\mathrm{Al}$ & $\mathrm{Cu}$ & $\mathrm{Co}$ & $\mathrm{Fe}$ \\
\hline SA508 & 0.16 & 0.27 & 1.43 & 0.77 & 0.23 & 0.52 & 0.003 & 0.02 & 0.04 & 0.004 & Bal. \\
Filler & 0.10 & 0.20 & 1.47 & 0.88 & 0.03 & 0.25 & 0.003 & 0.003 & 0.075 & - & Bal. \\
\hline
\end{tabular}

\subsection{Welding}

The details of the weld groove geometry and general set-up are shown in Figure 1.

The weld was completed by first making an autogenous root pass, which was followed by eight filling passes, as might be applied for a butt joint configuration in the $1 \mathrm{G}$ welding position. Shielding was provided by argon gas flowing at a rate of $81 / \mathrm{min}$. Owing to the self-restraint associated with the ligaments of material at either end of the groove, the specimens needed only light clamping during welding to prevent them from moving. A preheat/interpass temperature between 110 and $125^{\circ} \mathrm{C}$ was maintained.

The welding system consisted of an IPG fiber laser with a maximum power of $16 \mathrm{~kW}$, and a wire feeder. The beam parameter product for the laser was $10 \mathrm{~mm} . \mathrm{mrad}$. A defocused laser beam was used, with a spot diameter of $6 \mathrm{~mm}$ at the beam/material interaction point. The laser power values for the root pass and for the filling passes were 4.5 and $7 \mathrm{~kW}$, respectively. The welding speeds for the root pass and for the filling passes were 300 and $240 \mathrm{~mm} / \mathrm{min}$, respectively, while the average wire feed rate for the filling passes was $5 \mathrm{~m} / \mathrm{min}$.

In initial welding trials, the feasibility of employing a higher laser power for the root pass was explored. The authors had hoped to fuse a greater proportion of the joint 
thickness in the root pass, through careful design of the weld groove in conjunction with employing the laser in "keyhole" mode. This would have enhanced overall productivity through a reduction in the number of filling passes that would have been required to fill the joint. While it was possible to achieve an autogenous root bead with a thickness (or depth) in the order of $10 \mathrm{~mm}$, the authors found that root beads with high depth-to-width ratios were particularly prone to cracking upon cooling after welding. Thus, the welding parameters employed for the root pass in this work were selected on the basis that they produced root beads that were less likely to crack.

In both the root and the filling passes, a defocussed laser beam was used in conjunction with a welding speed that would be considered to be relatively low for laser welding. The authors found that the use of a focused beam led to insufficient heating of the groove walls and, consequently, significant levels of lack of fusion. The use of narrower weld grooves was also considered, but this would not have enabled the beam to reach the base of the groove without also impinging on the groove walls in other locations. As a result, the combination of a defocussed beam in conjunction with a modest travel speed was found to be the most effective method for avoiding lack of side-wall fusion, which is a defect that cannot be tolerated in critical nuclear welds. 

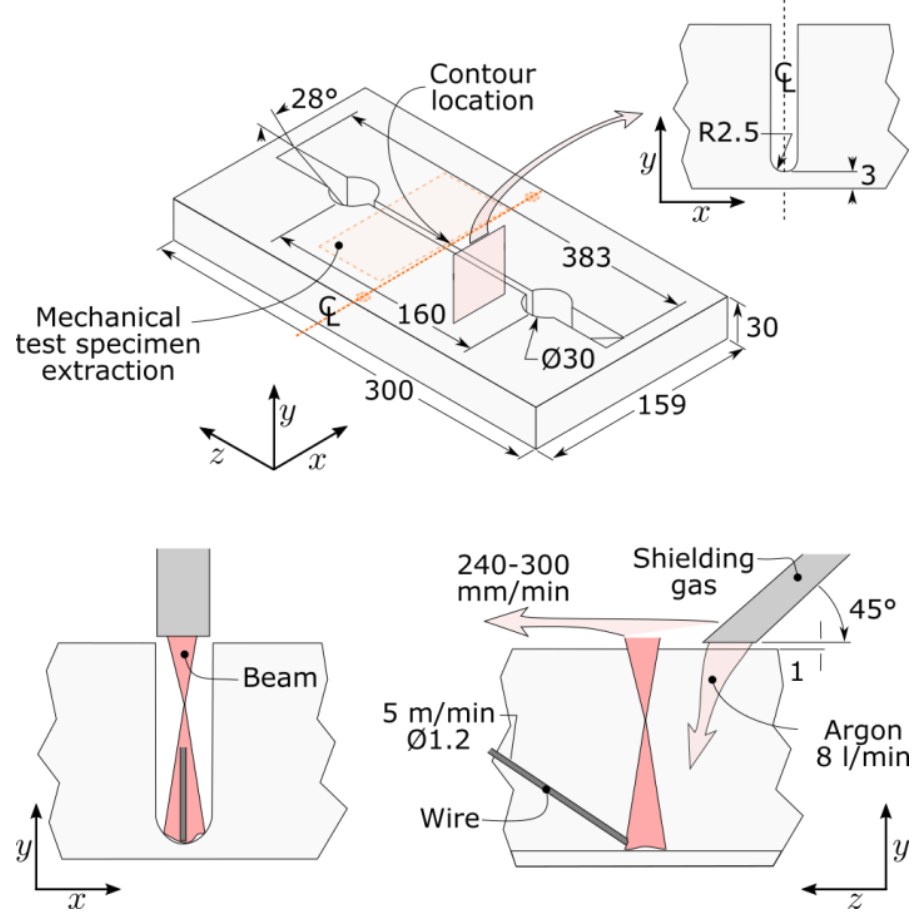

Figure 1: Configuration of test plates and welding set-up.

\subsection{Post-weld heat treatment (PWHT)}

After welding, two of the welds were subjected to a PWHT operation, while the other two were preserved in the as-welded (AW) condition. The PWHT procedure did not place restrictions on the heating and cooling rates below $300^{\circ} \mathrm{C}$, but the heating and cooling rates were restricted to a maximum of $20^{\circ} \mathrm{C}$ per hour between 300 and $607^{\circ} \mathrm{C}$, and the hold took place at a temperature of $607+/-13{ }^{\circ} \mathrm{C}$ for a duration of 2 hours. The stringent limits on heating and cooling rates at temperatures above $300^{\circ} \mathrm{C}$ were applied to ensure that the heat treatment practice was consistent with a heat treatment that would be applied to a real component, for which the generation of internal stresses during heat treatment would be an important consideration, owing to the much larger wall thicknesses that would be applicable. 
2.4 Metallography and hardness measurements

One specimen in the as-welded (AW) condition and one in the PWHT condition were allocated for the extraction of macrographs, and destructive residual stress measurements. The macrograph sections were etched using a solution of $5 \mathrm{ml}$ nitric acid and $95 \mathrm{ml}$ ethanol. Microstructural examination was carried out using a KEYENCE VHX-500F optical microscope. The variation in microhardness across the joints was measured using a Vickers microhardness machine (Durascan ${ }^{\mathrm{TM}}$ ) with a load of $0.5 \mathrm{~kg}$ and a dwell period of $15 \mathrm{~s}$. The nominal distances between indentations were $0.45-0.65 \mathrm{~mm}$ in the transverse (x) direction within the fusion zone, and $0.3 \mathrm{~mm}$ in the heat-affected zone (HAZ). In the through-thickness (y) direction, the nominal distance between indentations was $0.5-0.55 \mathrm{~mm}$ across all regions.

\subsection{Residual Stress Measurements}

The residual stresses were measured in the AW and PWHT conditions using the contour method. In both cases, residual stresses were measured on a plane that was orientated transversely to the welding direction, at the mid-length position of the weld (Figure 1). The contour cut involved sectioning of the samples perpendicular to the welding direction using electric discharge machining (EDM). The initial cut was made between two pilot holes, before the remaining ligaments at either edge of the specimen were cut. The surface contour profiles were measured using a Nanofocus laser scanner. The first step in the contour method analysis involved aligning and averaging the point clouds that were obtained from each side of the cut, followed by the fitting of bi-variate 
cubic splines to the region of the cut surface residing between the two pilot holes. A knot spacing of $4 \mathrm{~mm}$ was selected in both the $\mathrm{x}$ and $\mathrm{y}$ directions, on the basis that this produced a desirable compromise between minimising the overall fitting error while avoiding the overfitting problem; a root-mean-square error of $0.5 \mu \mathrm{m}$ was achieved. This spline was used to inform boundary conditions for a linear elastic finite element analysis. The mesh for this analysis described half of the plate (including the pilot holes), and comprised 193,000 second-order tetrahedral elements. Elements had edge lengths that varied from $1.6 \mathrm{~mm}$ at the cut surface to $30 \mathrm{~mm}$ along the longitudinal (z) direction. The values that were applied for the modulus and for Poisson's ratio were $210 \mathrm{GPa}$ and 0.27 , respectively. This contour method analysis was carried out according to current best practice [7].

\subsection{Cross-weld tensile testing}

Standard sub-size tensile coupons were extracted from the welded specimen in the PWHT condition for the purpose of determining the cross-weld tensile properties. Coupons were extracted from locations near to the top surface of the weld, as well as from the mid-thickness position (middle), and from a location near to the weld root (bottom). For benchmarking purposes, coupons were also extracted from parent material in the as-received condition, and after PWHT. Four cross-weld coupons were extracted from the weld at each through-thickness position (i.e. top, middle, bottom), and five specimens were extracted from the parent material in each condition. A schematic representation of 
the manner in which test coupons were extracted, together with the specimen dimensions, is given in Figure 2.

Prior to testing, the gauge length of each test coupon was prepared for two-dimensional digital image correlation (2D-DIC) with an application of a standard speckle pattern, and arranged so that an imaging spatial resolution of $22 \mu \mathrm{m}$ per pixel could be achieved. The tensile tests were carried out at $20^{\circ} \mathrm{C}$ in accordance with ASTM E8M 08 [8], applying a strain rate of 0.0003 per second, using an Instron 5569 test frame with a $50 \mathrm{kN}$ load cell. After each test, spatially resolved strain measurements were then calculated, using the VIC 2D software package with a subset size of $\sim 150 \mu \mathrm{m}$. This enabled the stress-strain behavior within distinct microstructural zones across the weld to be captured. In order to check the accuracy of the 2D-DIC analyses, an MTS extensometer with a $25 \mathrm{~mm}$ gauge length was also attached to each specimen during the tensile tests.

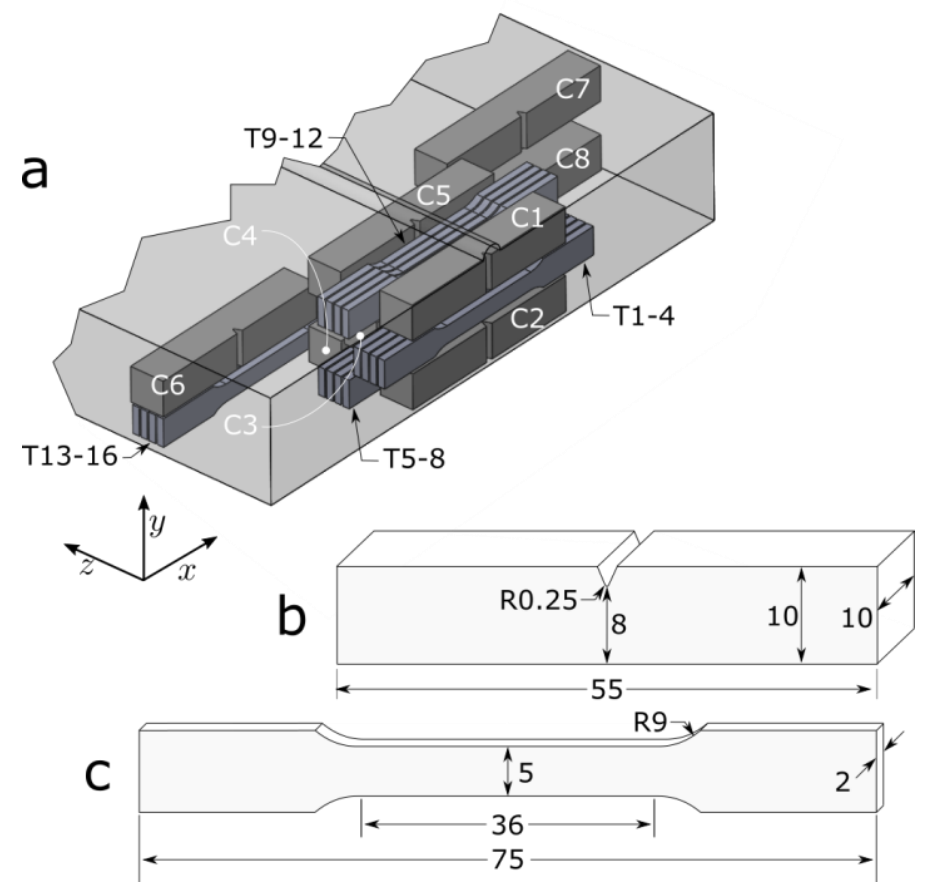

Figure 2: Schematic representation of (a) manner in which tensile and Charpy test coupons were extracted; (b) dimensions for Charpy test coupons and (c) dimensions for 
tensile test coupons. All dimensions are in millimetres.

\subsection{Toughness testing}

Standard Charpy impact test coupons were extracted and tested according to the ASTM E23 standard [9] at $20^{\circ} \mathrm{C}$. In all cases, coupons were extracted from the welded specimen in such a way that the notches were aligned with the weld centreline, with fracture propagating in a direction parallel to the welding direction (Figure 2). The number of coupons that could be extracted was limited by the availability of material. Two coupons were extracted from the top region of the weld, two from the bottom (i.e. the weld root) region, and one from mid-thickness region. In the case of the parent material, three specimens were extracted from as-received material and a further three were extracted from material that was subjected to PWHT.

\section{Results and discussion}

Macrographs of the multipass NGLW samples in the AW condition and after PWHT are shown in Fig. 3, together with the corresponding hardness maps. It can be seen that the welds appear to be sound. There was no lack of side-wall fusion or cracking, and no evidence of significant porosity. In the AW condition the HAZ appears to be more pronounced in the vicinity of the capping pass. This is due to the tempering effect associated with subsequent weld passes in multi-pass welding (i.e. the HAZs for all previous passes have been tempered). This tempering effect is also evident when the hardness of the HAZ for the capping pass is compared with the hardness of the HAZs for 
earlier passes. The hardness results suggest that the PWHT operation was effective. In comparison to data presented in Ref. [10], it can also be observed that the HAZ is narrower for NGLW than it is for gas-tungsten arc welding (GTAW).

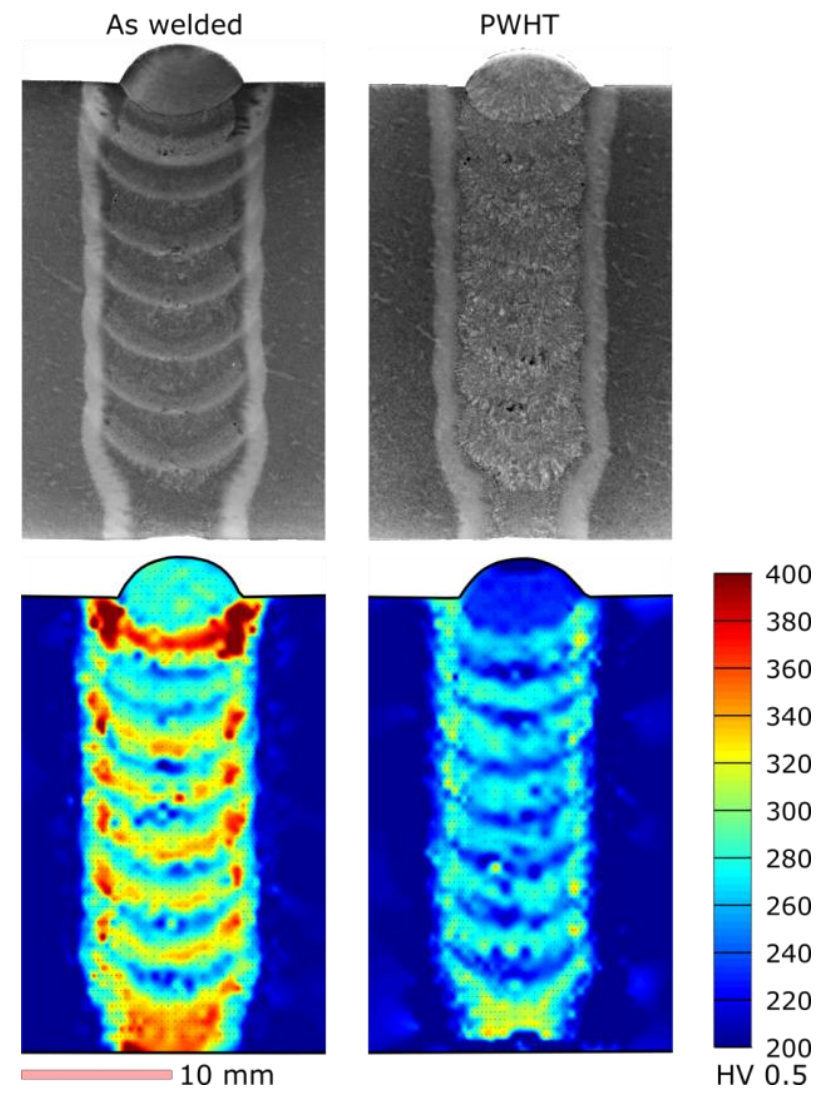

Figure 3: Macrographs (top) and hardness maps (bottom) for multipass NGLW samples in the as-welded condition (left) and after PWHT (right).

Optical micrographs were captured from each microstructural region across the welded joints, and these are shown in Figures 4a (as-welded condition) and 4b (after PWHT), for locations near the top surface of the weld and near to the mid-thickness position. The fusion zone and coarse-grained HAZ both appear to contain plate-like features, which is indicative of a microstructure that is either bainitic or martensitic, 
assuming that Widmanstätten ferrite is not present. The hardness values that were measured in the weld metal, for the last pass to be deposited, are consistent with the presence of bainite, while some of the reheated zones within the weld metal region produced hardness readings indicating that martensite is also present. The highest hardness values (> $400 \mathrm{HV}$ ) were recorded in the HAZ (i.e. within the parent material), presumably owing to the higher carbon content (Table 1). However, it is also clear that pass-to-pass tempering effects played a role in reducing the hardness within reheated weld metal.
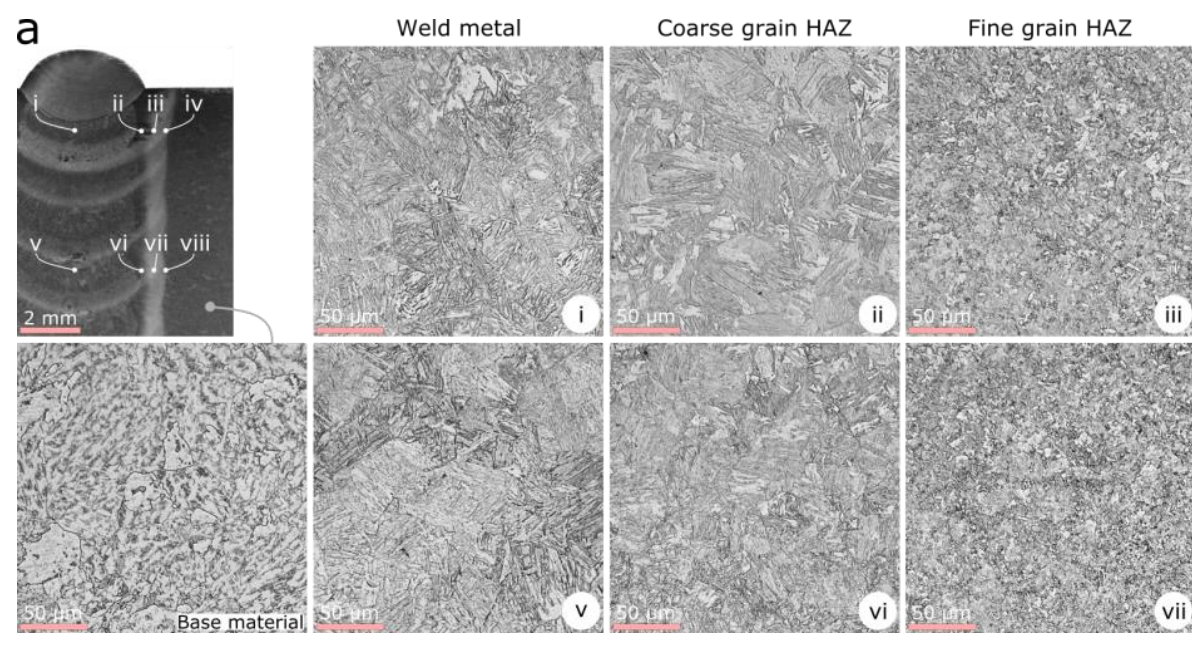

Intercritical HAZ

b
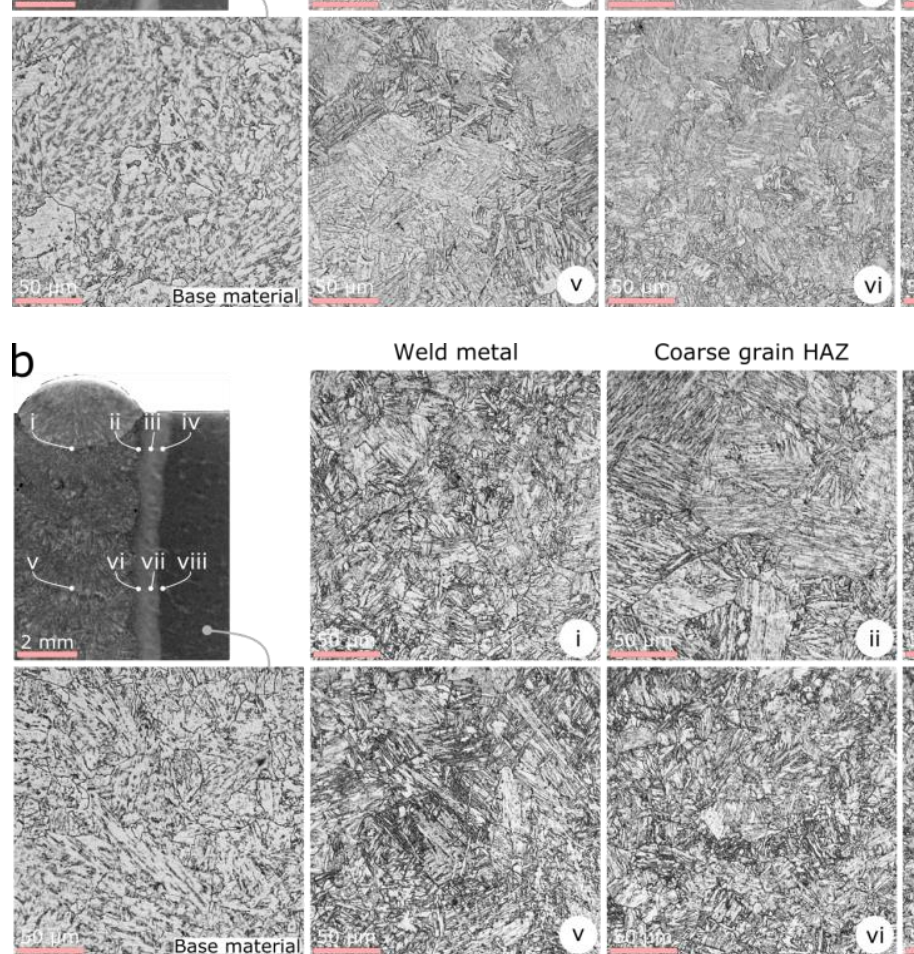

Weld metal

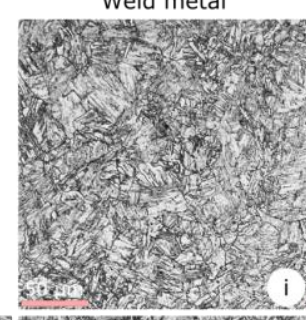

Coarse grain $\mathrm{HAZ}$

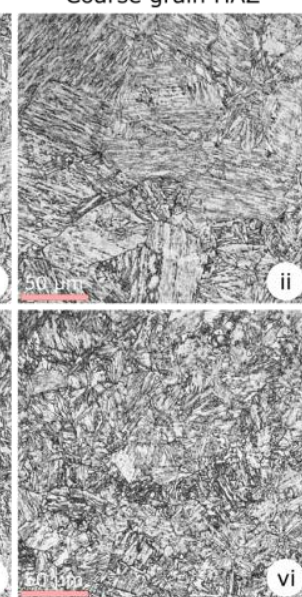

Fine grain $\mathrm{HAZ}$

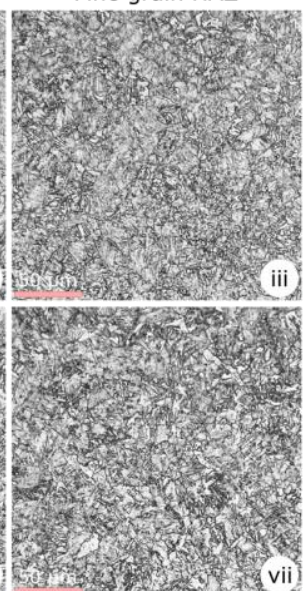

Intercritical HAZ

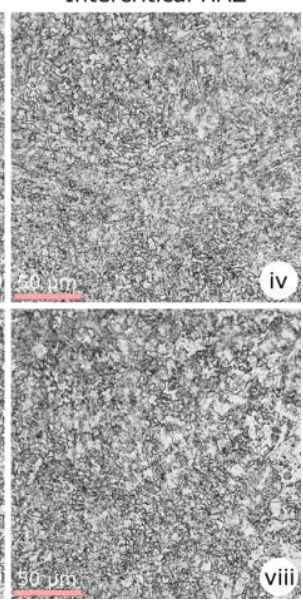

Figure 4: Optical micrographs obtained in different regions of the welded joints in (a) the 
as-welded condition and (b) the PWHT condition. The differences in microstructures obtained near to the top of the weld and near to the mid-thickness position did not appear to be significant.

The prior-austenite grain sizes in the fusion zone and coarse-grained HAZ appear to be in the order of $50 \mu \mathrm{m}$, which is similar to the grain size in the parent material. The detailed microstructures within the fine-grained and intercritical regions within the HAZ are more difficult to resolve, but the fine-grained HAZ is also likely to contain a significant proportion of bainite. The differences between the microstructures that were observed in the as-welded (Fig. 4a) and PWHT (Fig. 4b) conditions are not significant when viewed under an optical microscope, although they would be expected to be discernible with electron microscopy. However, detailed microstructural investigations were beyond the scope of the present study.

The residual stresses measured in the longitudinal direction (i.e. the stresses acting in a direction that is parallel to the welding direction) in the NGLW samples are shown in Figure 5, in both the as-welded condition and after PWHT. It can be seen that, in the as-welded condition, there is a region sustaining highly tensile residual stresses that generally coincides with the fusion zone, although this region is slightly offset from the weld centreline, being closer to the side of the plate corresponding to the start of the contour cut. Such an offset has been observed previously [11, 12], and has been attributed to the effects of cutting-induced plasticity during the EDM process $[13,14]$.

To a first order approximation, the stresses do not appear to vary significantly with distance through the thickness of the specimen. However, the stresses do clearly vary 
with increasing distance from the weld centerline, gradually becoming less tensile until low levels of compression are observed towards the edges of the plate. The magnitude of the residual stresses reduces significantly after PWHT, with peak stresses appearing to be in the order of $100-150 \mathrm{MPa}$.
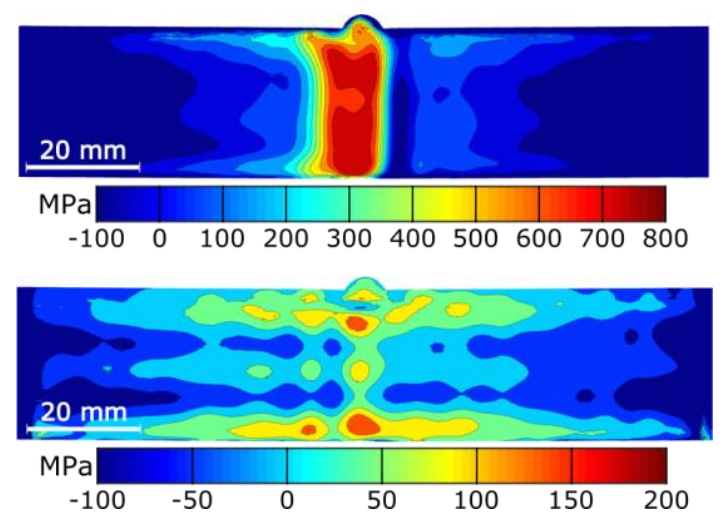

Figure 5: Longitudinal residual stresses as measured by the contour method in the as-welded condition (top) and after PWHT (bottom). The cutting direction was from left to right.

The general nature of the residual stress distributions in Figure 5 appears to be plausible. For example, the peak tensile stresses in a weld containing several passes would be expected to coincide with the fusion zone and HAZ. While pass-to-pass tempering effects are not evident in the residual stress distribution across the fusion zone in the as-welded condition, this in itself is not problematic, since residual stresses tend to be bound by the strength of the material, and the corresponding hardness map in Figure 3 suggests that the yield stress at all locations within the fusion zone comfortably exceeds the value for the parent material. However, one or two anomalies are evident on closer examination. Firstly, the peak stresses in the as-welded condition appear to be in the order of $700 \mathrm{MPa}$. This value appears to be slightly $(\sim 10 \%)$ higher than those typically 
reported for welds in SA508 steel $[10,15]$. It is possible that the narrow weld groove, together with the ligaments of material that remained in tact at either end of the specimen, led to high levels of constraint, and therefore contributed to the generation of high levels of stress. However, it must also be borne in mind that the initial EDM cut took place between two pilot holes, each of which was located towards an edge of the specimen (Figure 1). The ligaments of material that were located between each pilot hole and the adjacent edge of the plate were cut in separate cutting steps. Given that the residual stresses do not appear to have decayed to zero near to the edges of the plates, it is possible that making the EDM cuts on the measurement plane in a piecewise manner has introduced some errors to the final stresses, and that the magnitude of the peak tensile residual stresses in the multipass laser weld is therefore similar to the magnitudes that have been measured in welds made in SA508 Gr.3 Cl.1 steel using other welding processes (i.e. closer to $600 \mathrm{MPa}$ ).

Another anomaly in Figure 5 would appear to be the line-like region of compressive stress that is located near to the fusion zone, on the side of the specimen corresponding to the start of the cut. There is no obvious reason for the true residual stress distribution within the specimen to deviate from symmetry about the weld centerline in this manner. However, as was mentioned earlier, cutting-induced plasticity can introduce artifacts that manifest as asymmetry in the measured residual stress distribution [14]. Given that the region of peak tensile residual stresses is offset to some degree from the weld centerline, it would appear that cutting-induced plasticity has affected the measured stress 
distribution in some way. It is possible that the effects of cutting-induced plasticity have also led to the appearance of this localised region of compressive stress.

The tensile properties that were measured in the coupons that were extracted from the parent material, both in the as-received condition and after PWHT, are shown in Figure 6. The yield stress that was measured for the sample in the as-received condition is consistent with values that have been published previously [4]. It is also clear that subjecting the material to a further PWHT operation leads to a noticeable drop in the yield stress $(\sim 60 \mathrm{MPa})$, which must be borne in mind when interpreting the results of cross-weld tensile tests.

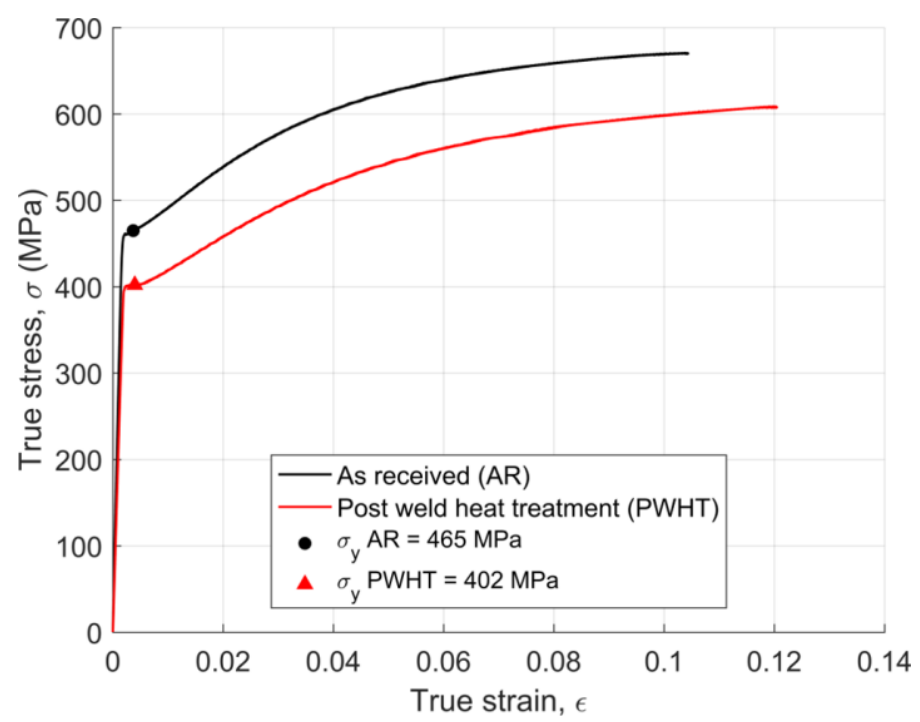

Figure 6: Plots of true stress versus true strain for parent material coupons in the as-received condition, and after PWHT.

Spatially resolved strain maps were produced based on the results that were obtained during the cross-weld tensile tests using digital image correlation. Figure 7 relates each metallurgical zone to the strain that was recorded, firstly, at the onset of yielding and, secondly, at the onset of fracture. The strain map corresponding to the onset of yielding 
reveals that yielding commenced in the parent material region. The strains in the fusion zone in particular, and the HAZ, were significantly lower than those recorded in the parent material at this stage of the test. However, some strain was still evident within the fusion zone because, in the early stages of the test, a considerable proportion of the total strain would have been elastic in nature. At the onset of fracture, however, the plastic deformation that occurred in the parent material, and to a lesser extent in the HAZ, dwarfed the elastic strain within the fusion zone, which did not yield during the cross-weld tensile tests.

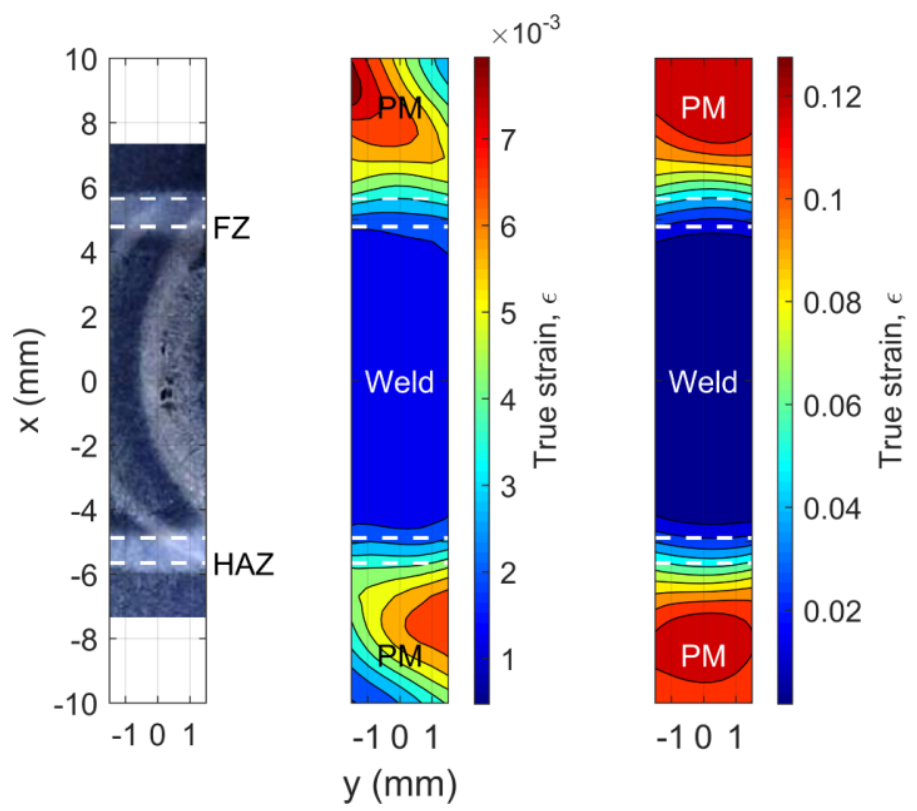

Figure 7: Strain localisation in a typical cross-weld tensile test. The microstructural zones (left) have been correlated with strain maps corresponding to the onset of yielding (middle) and the point at which the ultimate tensile strength is reached (right). Strain becomes highly concentrated within the parent material region as the test progresses.

Spatially-resolved true stress-true strain curves are plotted for each metallurgical zone in each region (i.e. top, middle or bottom) in Fig. 8. The stress-strain behavior for the parent material is distinguished from the behavior of the HAZ and the fusion zone or 
"weld". The plot for the composite behavior was based on a gauge length of $20 \mathrm{~mm}$.
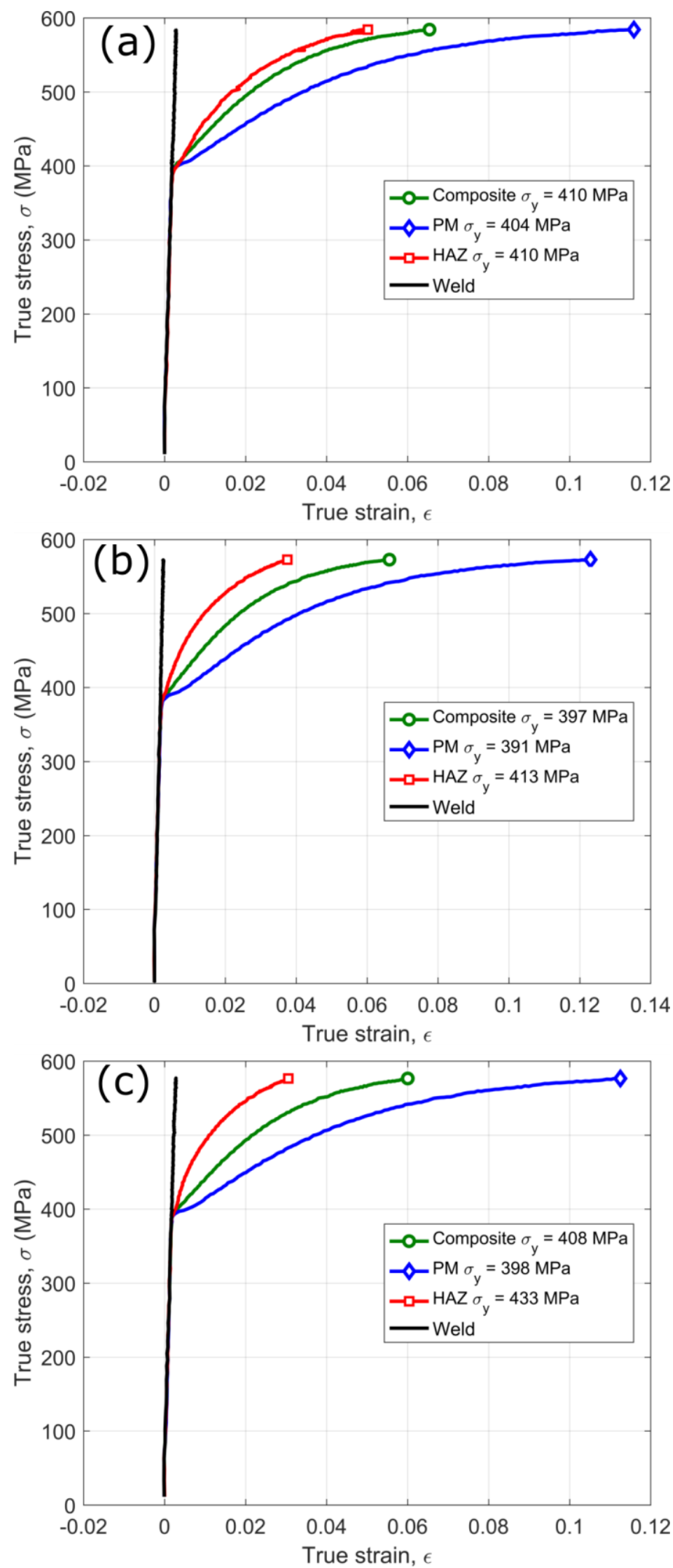

Figure 8: Spatially resolved true stress-true strain behavior from cross-weld tensile tests, 
for (a) the top region of the weld, (b) the middle region and (c) the bottom region.

It can be seen that the fusion zone did not undergo yielding anywhere throughout the thickness of the welded joint. It can also be seen that the HAZ was significantly stronger than the parent material. The composite behavior of the welded joint is not really a meaningful measure of the performance of the joint since the values that were recorded were dependent on the proportions of weld metal, HAZ and parent material within the gauge length. These proportions will vary with the gauge length that is chosen and, therefore, so will the composite properties. Nevertheless, for the purposes of comparison, the composite properties are included here based on a gauge length of $20 \mathrm{~mm}$. Unsurprisingly, these properties are intermediate between those of the parent material and HAZ region.

The variations in properties between different metallurgical zones, and also between different through-thickness regions of the weld, are plotted in Figure 9. The parent material can be seen to have a yield stress that is 10 to $15 \mathrm{MPa}$ lower than the yield stress for the HAZ. It must also be remembered that the yield stress for the fusion zone could not be included in this comparison because no yielding in this region was observed. While yielding did occur in the HAZ, the extent to which plastic flow occurred was significantly lower than it was the for parent material. The differences between the yield stresses for each of these regions will clearly have played a part in reducing the extent of plastic flow within the HAZ. However, it is also possible that plastic flow within the HAZ was inhibited by the adjacent (and very strong) fusion zone region, through constraint effects, particularly when consideration is given to the fact that the HAZ was only $\sim 1 \mathrm{~mm}$ wide. 

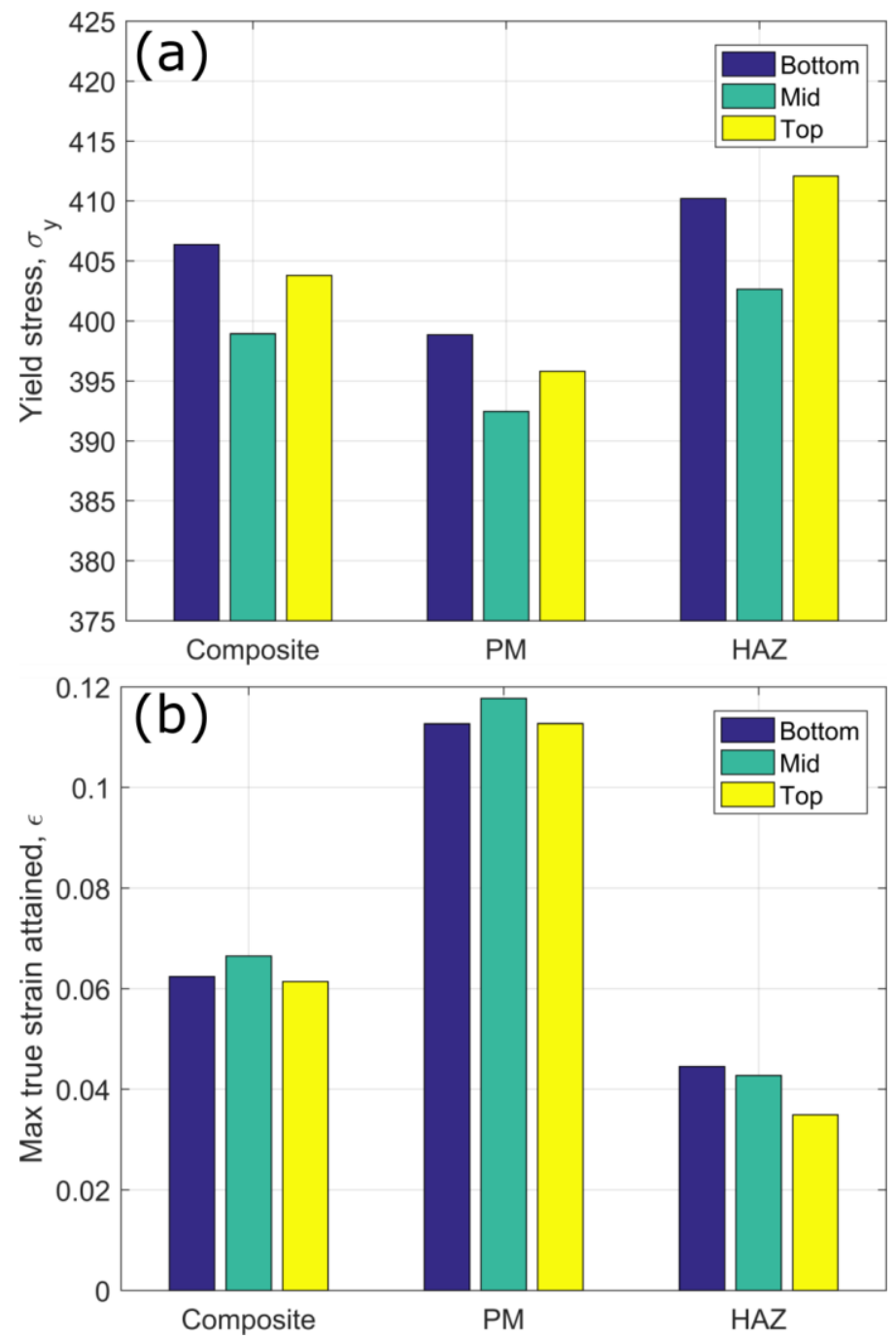

Figure 9: A comparison between the true stress-true strain behavior of different metallurgical zones in the cross-weld tensile tests: (a) the true yield stress and (b) the maximum true strain attained.

While there were differences between the values for yield stress that were measured in the top, middle and bottom regions of the weld, these differences were relatively small $(5-10 \mathrm{MPa})$. The though-thickness variations in the extent to which plastic flow occurred were also small. In general, the yield stress appeared to be slightly lower in the mid-thickness position of the weld. This is likely to be related to the fact that there were 
reduced pass-to-pass tempering effects for the HAZs associated with the last weld beads to be deposited (i.e. at the top of the weld), while the different welding parameters and weld bead profile that were applied in making the root pass also appear to have led to a reduced pass-to-pass tempering effect, since elevated hardness values persisted in this region. The localized regions of increased hardness are evident in the hardness maps in Figure 3.

A summary of the results of Charpy impact testing is given in Table 2. Interestingly, it can be seen that the PWHT operation had a significant effect on the impact energies that were recorded for the parent material, since these increased on average by $30-40 \%$ after PWHT. It should be noted, however, that there appeared to be significant scatter in the impact energies recorded by the parent material after PWHT. Perhaps more significantly, the impact energies that were recorded for those samples with notches on the weld centerline were higher than those for the parent material in the as-received condition. This suggests that both the strength and toughness of the weld metal would not present reasons for concern from a structural integrity standpoint. It would appear that the fine distribution of carbides that is produced by the NGLW process leads to a superior combination of strength and toughness than is achieved within the parent material. Although there did appear to be small differences in the impact energies that were recorded in different through-thickness positions within the weld, these differences are unlikely to be statistically significant given that a maximum of only two tests was carried out in each region. 
Table 2: Summary of results for Charpy Impact tests on weld test pieces at $20^{\circ} \mathrm{C}$. All tests on the weld zone were carried out on material that had undergone PWHT.

\begin{tabular}{|c|c|c|c|c|}
\hline $\begin{array}{l}\text { Specimen } \\
\text { ID } \\
\end{array}$ & Location & $\begin{array}{c}\text { Impact } \\
\text { Energy }(\mathrm{J})\end{array}$ & $\begin{array}{c}\text { Avg. Impact Energy }(\mathrm{J}) \\
\text { in each location }\end{array}$ & $\begin{array}{c}\text { Overall Avg. } \\
\text { Impact Energy (J) }\end{array}$ \\
\hline $\mathrm{C}-1$ & \multirow{2}{*}{ Top of weld } & 232 & \multirow{2}{*}{223} & \multirow{5}{*}{211} \\
\hline C-4 & & 213 & & \\
\hline $\mathrm{C}-3$ & Middle of weld & 199 & 199 & \\
\hline $\mathrm{C}-2$ & \multirow{2}{*}{ Bottom of weld } & 210 & \multirow{2}{*}{206} & \\
\hline $\mathrm{C}-5$ & & 201 & & \\
\hline $\mathrm{C}-6$ & \multirow{3}{*}{$\begin{array}{c}\text { Base metal - } \\
\text { PWHT } \\
\text { condition } \\
\end{array}$} & 297 & \multirow{3}{*}{255} & \multirow{3}{*}{255} \\
\hline $\mathrm{C}-7$ & & 212 & & \\
\hline $\mathrm{C}-8$ & & 255 & & \\
\hline BMC-1 & \multirow{3}{*}{$\begin{array}{l}\text { Base metal - } \\
\text { As-received } \\
\text { condition }\end{array}$} & 168 & \multirow{3}{*}{179} & \multirow{3}{*}{179} \\
\hline BMC-2 & & 167 & & \\
\hline BMC-3 & & 201 & & \\
\hline
\end{tabular}

\section{Concluding Remarks}

In this work, high quality welded joints in $30 \mathrm{~mm}$ thick SA508 Gr. $3 \mathrm{Cl} .1$ steel have been successfully manufactured using the multipass NGLW process. The welds were found to be free of lack-of-fusion defects and free of any significant porosity. The weld metal was found to exhibit a desirable combination of strength and toughness, appearing to match or exceed the properties of the parent material in each case. The longitudinal residual stresses were highly tensile throughout the fusion zone, being in the order of the ultimate tensile strength for SA508 Gr. $3 \mathrm{Cl}$. 1 steel. This is comparable to the peak tensile stresses that are measured in multipass arc welds in the same steel. While for multipass arc welds, the highest tensile residual stresses tend not to arise across the entirety of the fusion zone, it must be remembered that the extent of the fusion zone will be smaller for multipass 
NGLW than it will for an arc welding process. The residual stresses associated with NGLW were substantially reduced by PWHT, to levels in the order of $100-150 \mathrm{MPa}$, which again is consistent with what has been observed for arc welds. While further work should be carried out to assess the toughness of the HAZ, the results obtained in this work suggest that, from a materials performance standpoint, the multipass NGLW can produce welds of a quality that is suitable for critical nuclear components.

Based on the findings in this work, the attractiveness of multipass NGLW as a candidate process for the manufacture of critical nuclear pressure vessels is likely to be decided by factors unrelated to the properties of the resulting welds. These might include the reliability of the process with respect to the avoidance of defects such as lack-of-fusion, the economics of the process in comparison to alternatives, its tolerance to poor joint fit-up, and the ease with which the process can be integrated into the manufacturing sequence. In these respects, the picture is less clear. For example, the fact that less filler material is required for a joint of a given thickness, when compared to submerged arc welding, is offset by the fact that submerged arc welding can achieve higher deposition rates. The weld groove will be smaller for multipass NGLW than it will for arc welding processes, but this means that more precise alignment of the faying surfaces will be required over the entire weld seam, in components that are typically very large. It can also present challenges for the effective delivery of shielding gas to the weld zone, particularly as the thickness of the joint increases. There is, therefore, the possibility that benefits associated with reductions in the widths of the fusion zone and HAZ will not 
be sufficiently attractive to justify the necessary investments in equipment, and in compliance with more stringent fit-up requirements.

Another natural competitor to multipass NGLW is electron beam welding. Recent developments in the development of Reduced Pressure Electron Beam (RPEB) welding have enabled large pressure vessels to be joined in a single weld pass, using a local sealing system, so that it is not necessary to place a large pressure vessel inside a vacuum chamber $[1,16]$. This approach offers a step change in productivity in comparison to arc welding processes in a way that multipass NGLW is unlikely to do, since thick sections (> $\sim 100 \mathrm{~mm}$ ) of material can be welded in a single weld pass, without the need to add filler material. A square-butt weld configuration is also likely to be more attractive than a narrow weld groove. The application of RPEB welding will clearly require substantial investments in capital equipment, and further development, when compared to arc-based welding processes. However, the potential benefits associated with RPEB welding are also much easier to identify than they are for mutlipass NGLW.

The primary motivation for this work was to establish the feasibility of applying a laser-based process to the joining of nuclear pressure vessels steels. It would appear that there are no obstacles from the standpoint of materials performance. However, when a laser is applied to a multipass weld in which the addition of filler material is required, many of the advantages that are traditionally associated with laser welding are either greatly reduced or substantially offset by the introduction of other complications. These challenges will need to be met with elegant solutions if multipass NGLW is to emerge as 
a leading option for thick section welding of pressure vessel steels.

\section{Acknowledgments}

The authors gratefully acknowledge financial support provided by the Engineering and Physical Sciences Research Council through the NNUMAN programme grant in nuclear manufacturing (Grant number: EP/J021172/1). The authors are also grateful for technical assistance from Dr. Joanna Walsh, Mr. Ian Winstanley and Mr. Paul English, and for support from Ms. J. Grant.

\section{References}

[1] K. R. Ayres, P. R. Hurrell, C. M. Gill, K. Bridger, L. D. Burling, C. S. Punshon, Liwu

Wei and N. Bagshaw: "Development of Reduced Pressure Electron Beam Welding Process for Thick Section Pressure Vessel Welds”, Paper PVP2010-25957, Proceedings of the ASME 2010 Pressure Vessels and Piping Division Conference, Bellevue, Washington, USA, July 18-22, 2010.

[2] I.S. Kim and S.S. Kang, Int. J. Press. Vess. Piping 62 (1995) 123-129.

[3] Kim SH, Im YR, Lee SH, Lee HC, Oh YJ and Hong JH. Effects of alloying elements on mechanical and fracture properties of base metals and simulated heat-affected zones of SA508 steels. Metall Mater Trans A 2001;32A:903-911.

[4] B.S. Lee, M.C. Kim, J.H. Yoon and J.H. Hong, Int. J. Press. Vess. Pip. 87 (2010) $74-80$. 
[5] W. Guo, S.Y. Dong, W. Guo, J.A. Francis, L. Li., Mater. Sci. Eng.A 625 (2015) 65-80.

[6] J.A. Francis, H.K.D.H. Bhadeshia and P.J. Withers, Mater. Sci. Technol. 23 (2007)

1009-1020.

[7] F. Hosseinzadeh, J. Kowal and P. J. Bouchard, Towards good practice guidelines for the contour method of residual stress measurement, J. Eng. (2014), doi:10.1049/joe.2014.0134.

[8] ASTM E8M 08, Standard Test Methods for Tension Testing of Metallic Materials,

American Society for Testing and Matetrials, 2008.

[9] ASTM E23, Standard Test Methods for Notched Bar Impact Testing of Metallic

Materials, American Society for Testing and Matetrials, 2016.

[10] A.F. Mark, J.A. Francis, H. Dai, M. Turski, P.R. Hurrell, S.K. Bate, J.R. Kornmeier, P.J. Withers, Acta. Mater. 60 (2012) 3268-3278.

[11] Y. Traoré, F. Hosseinzadeh, and P. J. Bouchard: 'Plasticity in the contour method of residual stress measurement', Adv. Mater. Res., 2014, 996, 337-342.

[12] W. Guo, J.A. Francis, L. Li, A.N. Vasileiou, D. Crowther and A. Thompson, Residual stress distributions in laser and gas-metal-arc welded high-strength steel plates, Materials Science and Technology (2016), 32 (14), pp 1449-1461. DOI: $10.1080 / 02670836.2016 .1175687$

[13] O. Muransky, C.J. Hamelin, F. Hosseinzadeh and M.B. Prime, "Mitigating Cutting-Induced Plasticity in the Contour Method. Part 2: Numerical Analysis", International Journal of Solids and Structures (2016), 94-95, 254-262.

[14] Y.L. Sun, M.J. Roy, A.N. Vasileiou, M.C. Smith, J.A. Francis and F. Hosseinzadeh, "Evaluation of Errors Associated with Cutting-Induced Plasticity in Residual Stress 
Measurements Using the Contour Method”, Experimental Mechanics (2017) 57, pp. 719. DOI:10.1007/s11340-017-0255-5

[15] D.J. Smith, G. Zheng, P.R. Hurrell, C.M. Gill, B.M.E. Pellereau, K. Ayres, D. Goudar and E. Kingston, International Journal of Pressure Vessels and Piping, Volumes 120-121, August-September 2014, Pages 66-79.

[16] A. S. Sanderson, C. S. Punshon and J. D. Russell: “Advanced welding processes for fusion reactor fabrication”, Fusion Engineering and Design, 49-50, pp. 77-87, 2000. 